\title{
Association of Hypokalaemia and Hypophosphataemia
}

\author{
D. C. ANDERSON,*§ M.B., M.R.C.P.(ENG., ED.); T. J. PETERS, ${ }^{\dagger} \dagger$ M.B., M.SC., M.R.C.P.(ENG., ED.) \\ W. K. STEWART, $\ddagger$ M.B., M.R.C.P.(ENG., ED)
}

British Medical fournal, 1969, 4, 402-403

\begin{abstract}
Summary : A prospective study of 13 patients with hypokalaemia due to a variety of causes demonstrated that six had hypophosphataemia. In 10 patients the plasma inorganic phosphate level rose on correction of the hypokalaemia. Before treatment seven patients had an excessive rate of excretion of phosphate relative to creatinine in the urine. Following correction of the hypokalaemia 11 patients had an increase in renal tubular reabsorption of phosphate relative to creatinine. It is suggested that hypokalaemia may be causally related to the hypophosphataemia, and that in chronic potassium depletion this may affect bone mineralization.
\end{abstract}

\section{Introduction}

Many factors may affect the plasma levels of potassium and inorganic phosphate either separately or together. For example, corticosteroids may cause an intracellular shift of potassium (Bagsnawe, Curtis, and Garnett, 1965) while also increasing the renal excretion of phosphate and potassium (Camanni, Losana, Massara, and Molinatti, 1967 ; Steelman and Hirschmann, 1967). Administration of glucose and insulin causes a movement of both ions into cells (Hoffman, 1964). In renal failure the plasma levels tend to rise in parallel (Goldman and Bassett, 1954), and in renal tubular acidosis the urinary excretion of both ions is increased.

Hypophosphataemia due to renal phosphate loss was attributed to potassium depletion itself in a patient with potassium-losing renal disease by Mahler and Stanbury (1956). On potassium repletion the plasma potassium and phosphate levels rose in parallel, but the patient was acidotic, and the plasma bicarbonate level rose at the same time. Gordon and Eichenholtz (1961) described a case of potassium depletion and alkalosis due to Conn's syndrome, with associated hypophosphataemia and high phosphate clearance; they ascribed the latter to excess tubular bicarbonate competing with phosphate for reabsorption, and not to hypokalaemia or potassium depletion. After observing the association of hypokalaemia and hypophosphataemia in an acidotic patient with ureterosigmoidostomy we decided to investigate prospectively plasma phosphate changes and the renal tubular handling of phosphate in an unselected series of patients with hypokalaemía from a variety of causes, both before and after potassium repletion.

\section{Methods}

All patients entering a general medical ward were screened for hypokalaemia. Thirteen patients with a plasma potassium level of less than $3 \mathrm{mEq} / \mathrm{l}$. and a blood urea of less than $65 \mathrm{mg} . / 100 \mathrm{ml}$. were studied. In each of these patients serial

\section{* Medical Registrar.}

t Lecturer in Medicine.

‡ Senior Lecturer in Medicine.

Department of Medicine, University of Dundee, Angus, Scotland.

Present address: Department of Medicine, Royal Postgraduate Medical School, London W.12. plasma samples were collected daily at 9 a.m. and urine samples from 8 to 10 a.m. Measurements of potassium, bicarbonate, inorganic phosphate, and creatinine were made by the usual autoanalyser methods. The phosphate excretion index (P.E.I.) was also determined serially (Nordin and Fraser, 1960). The tubular reabsorption of phosphate, expressed as mg. of phosphorus reabsorbed per $100 \mathrm{ml}$. of glomerular filtrate $(\% \mathrm{TRP} \times \mathrm{P})$, was also calculated (Thomas, Connor, and Morgan, 1958) using the formula :

$\% \mathrm{TRP} \times \mathbf{P}(\mathrm{mg} . \mathrm{P} / 100 \mathrm{ml}$. of glomerular filtrate $)=$

$$
\left[1-\frac{\mathrm{Up} \times \mathrm{P}_{\mathrm{cr}}}{\mathrm{Pp} \times \mathrm{Ucr}_{\mathrm{c}}}\right] \times \mathrm{Pp}
$$

where $U p=$ Urine phosphate $(\mathrm{mg} . / 100 \mathrm{ml}$. ), Ucr $=$ Urine creatinine (mg./100 ml.), $\mathrm{Pp}=$ Plasma phosphate (mg./ $100 \mathrm{ml}.), \mathrm{Pcr}=$ Plasma creatinine $(\mathrm{mg} . / 100 \mathrm{ml}$.$) .$

Hypokalaemia was corrected by removing any obvious cause -for example, diuretics-and by supplementing the ordinary ward diet with potassium chloride (Slow-K). Neither phosphate nor vitamin D supplements were given.

\section{Results}

The values before and after correction of the hypokalaemia are shown in the Table. The "depleted state" figures are the estimations on the earliest plasma sample for which all data are available. The "repleted state" figures are from the sample which showed the highest potassium level. Of the 13 hypokalaemic patients six had hypophosphataemia, and in all but one the plasma phosphate level returned to normal during potassium repletion. In 10 of the patients there was a rise in the plasma phosphate level concurrent with the increase in plasma potassium level.

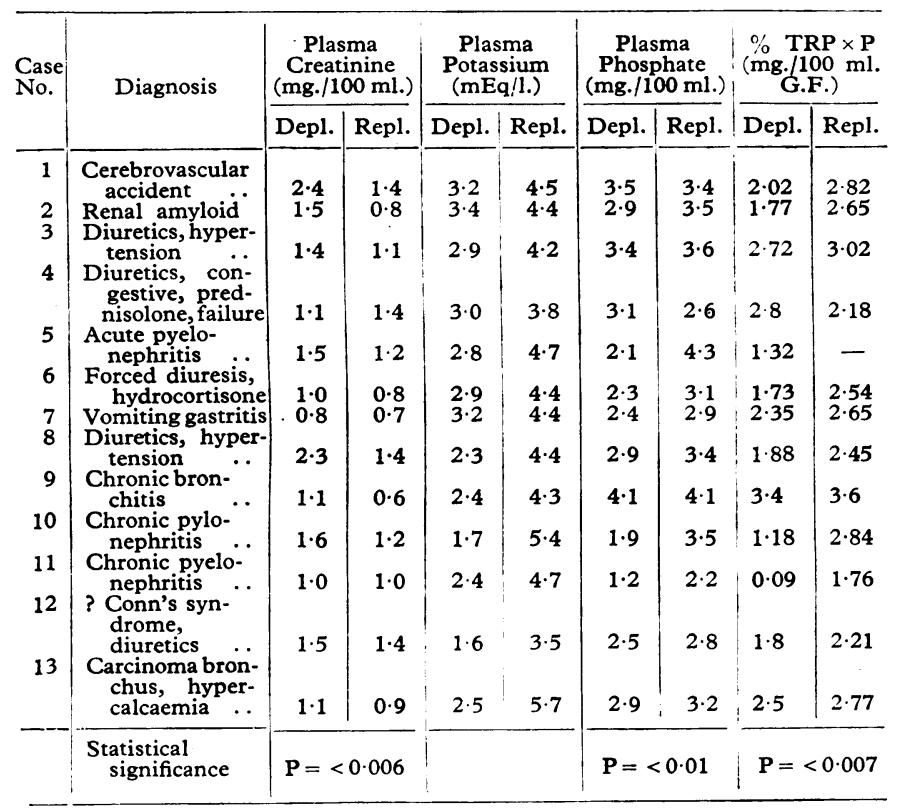


Seven patients while in the hypokalaemic phase had a reduced \% TRP $\times \mathrm{P}$ (below $2 \cdot 1 \mathrm{mg} . / 100 \mathrm{ml}$.) and eight had a raised PEI (above 0.09). After correction of the hypokalaemia 11 patients showed a rise in the \%TRP $\times P$ and 10 had a fall in the PEI, which suggests that reduction in the amount of phosphaturia had occurred.

These results are shown graphically (see Chart). The change in plasma potassium $(\Delta-\mathbf{K})$ is plotted (a) against the corresponding change in plasma phosphate $(\Delta-\mathrm{P}),(\mathrm{b})$ against $\Delta-\% \mathrm{TRP} \times \mathrm{P}$, and (c) against $\Delta-\mathrm{PEI}$. In (d) the change in plasma phosphate $(\Delta-\mathrm{P})$ is plotted against the corresponding change in plasma bicarbonate $\left(\Delta-\mathrm{HCO}_{3}\right)$. Statistical analysis of the data (by the $\chi^{2}$ test) indicates a significant association ( $\mathrm{P}<0.05$ ) between $\Delta-\mathrm{K}: \Delta-\mathrm{P}, \Delta-\mathrm{K}: \Delta-\% \mathrm{TRP} \times \mathrm{P}$, and $\Delta-\mathrm{K}: \Delta-\mathrm{PEI}$. There appears to be no association between $\Delta-\mathrm{P}$ and $\Delta-\mathrm{HCO}_{3}$.
๑

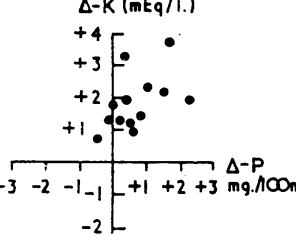

$$
x^{2}=5.33 \quad p<0.05
$$

(c)

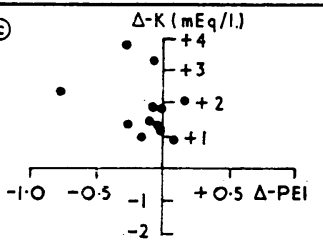

$x^{2}=5.33 \quad P<0.05$
$\Delta-K(m E q / I$. (b)

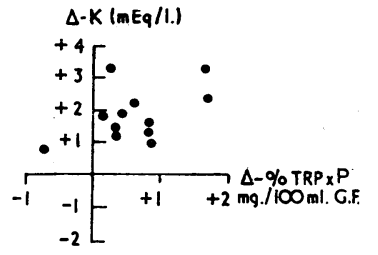

$x^{2}=8.33 \quad P<0.01$

(d)

(4)

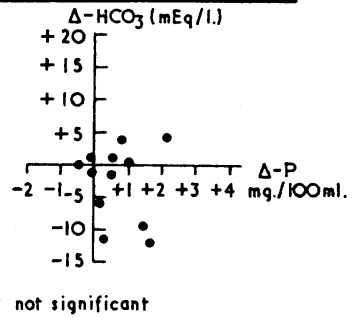

\section{Discussion}

Our results suggest that in hypokalaemic states, whether associated with alkalosis or not, there is a decrease in plasma phosphate level which is probably due to increased phosphaturia. The evidence for increased renal phosphate loss in our patients is indirect and depends on observed changes in two indices (PEI and \% TRP $\times \mathrm{P}$ ), both of which relate phosphate clearance to creatinine clearance. The initial level of plasma creatinine was in most cases slightly raised, falling subsequently; this may represent the mildly reduced creatinine clearance often found in potassium depletion (Relman and Schwartz, 1958). The observed changes in PEI and $\%$ TRP $\times P$ can therefore be explained in part by an initially low creatinine clearance which subsequently rose to normal. Nevertheless, the finding of a rise in plasma phosphate level on correction of hypokalaemia makes it likely that raised phosphate clearance was also present in the hypokalaemic state. Increased phosphaturia and negative phosphate balance has been observed in experimental potassium depletion in man whether the subjects were alkalotic (Black and Milne, 1952) or acidotic (Fourman, 1954 ; Lennon and Lemann, 1968).

Other factors may have affected phosphate metabolism in some of the cases; thus four had become hypokalaemic following use of diuretics, some of which can increase excretion of phosphate as well as potassium (Duarte and Bland, 1965). Two patients were on corticosteroids-Case 6 in the hypokalaemic phase alone, and Case 4 throughout. Case 13 had a bronchial carcinoma and hypercalcaemia, but the phosphate changes appeared more closely related to changes in serum potassium than to fluctuations in serum calcium levels.

Hypophosphataemia in hypokalaemic states may be of importance. Experimental potassium depletion in chickens is accompanied by a decrease in bone ash due to a reduced phosphate content (Rinehart, Rogler, and Featherston, 1968). Hypophosphataemia is probably a major factor in the osteomalacia which complicates ureterosigmoidostomy (Anderson, Peters, and Stewart, unpublished), though here acidosis, as well as hypokalaemia and potassium depletion, is probably important.

We are grateful to Professor Sir Ian Hill for permission to study patients under his care, to Professor P. D. Griffiths and his staff for the biochemical investigations, and to Professor H. G. Morgan for his helpful criticism. Requests for reprints should be sent to Dr. W. K. Stewart.

\section{REFERENCES}

Bagshawe, K. D., Curtis, J. R., and Garnett, E. S. (1965). Lancet, 1, 18.

Black, D. A. K., and Milne, M. D. (1952). Clinical Science, 11, 397.

Camanni, F., Losana, O., Massara, F., and Molinatti, G. M. (1967). Acta Endocrinologica, 56, 85.

Duarte, C. G., and Bland, J. H. (1965). Metabolism, 14, 211.

Fourman, P. (1954). Clinical Science, 13, 93.

Goldman, R., and Bassett, S. H. (1954). Fournal of Clinical Investigation, 33, 1623 .

Gordon, G. B., and Eichenholtz, A. (1961). fournal of Laboratory and Clinical Medicine, 57, 257.

Hoffman, W. S. (1964). The Biochemistry of Clinical Medicine, 3rd ed., p. 93. Chicago, Year Book Medical Publishers.

Lennon, E. J., and Lemann, J., jun. (1968). Clinical Science, 34, 365.

Mahler, R. F., and Stanbury, S. W. (1956). Quarterly fournal of Medicine, $25,21$.

Nordin, B. E. C., and Fraser, R. (1960). Lancet, 1, 947.

Relman, A. S., and Schwartz, W. B. (1958). American fournal of Medicine, 24, 764.

Rinehart, K. E., Rogler, J. C., and Featherston, W. R. (1968). Fournal of Nutrition, 96, 231 .

Steelman, S. L., and Hirschmann, R. (1967). In The Adrenal Cortex, edited by A. B. Eisenstein, p. 345 . London, Churchill.

Thomas, W. C., jun., Connor, T. B., and Morgan, H. G. (1958). fournal of Laboratory and Clinical Medicine, 52, 11 . 